\title{
Chemical Analysis of Plutonium-238 for Space Applications
}

\author{
Amy S. Wong \\ Nuclear Materials Technology Division, Los Alamos National \\ Laboratory, Los Alamos, New Mexico 87545
}

\begin{abstract}
Los Alamos National Laboratory (LANL) has produced general-purpose heat sources (GPHS) containing plutonium-238 oxide for space and terrestrial uses over the past two decades. Power Source Technologies Group (NMT-9) has full capabilities to both recover and purify ${ }^{238} \mathrm{PuO}_{2}$ from scrap and aged fuels and to fabricate oxides into fuel pellets for heat sources.
\end{abstract}

Analytical chemistry supports processing monitoring and product certification for ${ }^{238} \mathrm{Pu}$ operations. The ${ }^{238} \mathrm{Pu}$ oxides are dissolved and submitted for plutonium assay $(\% \mathrm{Pu})$, actinide impurity ${ }^{236} \mathrm{Pu},{ }^{237} \mathrm{~Np}$, ${ }^{234} \mathrm{U}$, and ${ }^{241} \mathrm{Am}$ ), plutonium isotopic composition, and non-actinide cationic and anionic impurities analyses. The data obtained from these measurements provide baseline parameters for processing, waste disposal, and product certifications.

Due to source term and material-at-risk issues at the aging CMR Facility (Chemistry Metallurgy Research building), we began the process of relocating ${ }^{238} \mathrm{Pu}$ analytical capabilities to the Plutonium Facility at TA-55 in 1999. In addition, we are installing several in-line processing monitoring capabilities in the full-scale aqueous scrap recovery operation.

In this paper, an overview of chemical analysis capabilities that support ${ }^{238} \mathrm{Pu}$ programs and the progress of establishing these capabilities at the Plutonium Facility will be discussed. These chemical and in-line analysis capabilities include UV-visible spectrometry, gamma-ray spectrometry, alpha spectrometry, direct-current arc (DC Arc), inductively coupled plasma mass spectrometry (ICP-MS), plutonium process monitoring (PPM) system for ion exchange operation, and solution in-line alpha counter (SILAC) for gross alpha determination of aqueous solutions.

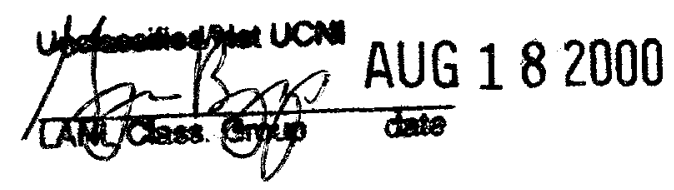




\section{DISCLAIMER}

This report was prepared as an account of work sponsored by an agency of the United States Government. Neither the United States Government nor any agency thereof, nor any of their employees, make any warranty, express or implied, or assumes any legal liability or responsibility for the accuracy, completeness, or usefulness of any information, apparatus, product, or process disclosed, or represents that its use would not infringe privately owned rights. Reference herein to any specific commercial product, process, or service by trade name, trademark, manufacturer, or otherwise does not necessarily constitute or imply its endorsement, recommendation, or favoring by the United States Government or any agency thereof. The views and opinions of authors expressed herein do not necessarily state or reflect those of the United States Government or any agency thereof. 


\section{DISCLAIMER}

Portions of this document may be illegible in electronic image products. Images are produced from the best available original document. 


\title{
Chemical Analysis of Plutonium-238 for Space Applications
}

\author{
Amy S. Wong \\ Nuclear Materials Technology Division, MS E502, Los Alamos National Laboratory, Los Alamos, NM 87545 \\ Phone: 505-667-7373,Email: wong@lanl.gov
}

\begin{abstract}
In this paper, an overview of chemical analysis capabilities that support ${ }^{238} \mathrm{Pu}$ programs for space applications and the progress of establishing these capabilities at the Los Alamos Plutonium Facility will be discussed. These chemical and in-line analysis capabilities include (1) UV-visible spectrometry for Pu Assay, (2) nuclear detection systems (integrated gamma-ray and alpha spectrometry, and gas proportional counter) for radiochemical analysis, (3) direct-current arc (DC Arc) and inductively coupled plasma mass spectrometry (ICP-MS) for trace analysis, (4) plutonium process monitoring (PPM) system for ion-exchange operations, and (5) solution in-line alpha counter (SILAC) for gross alpha determination of aqueous solutions.
\end{abstract}

\section{INTRODUCTION}

Los Alamos National Laboratory (LANL) has produced general-purpose heat sources (GPHS) containing plutonium-238 oxide for space and terrestrial uses over the past two decades. Power Source Technologies Group (NMT-9) has full capabilities to recover and purify ${ }^{238} \mathrm{PuO}_{2}$ from aged fuels and scrap and to fabricate purified oxides into fuel pellets for heat sources. Analytical chemistry supports process monitoring and product certification for ${ }^{238} \mathrm{Pu}$ operations. The ${ }^{238} \mathrm{Pu}$ oxides are dissolved and submitted for plutonium assay (\% Pu), actinide impurity

$\left({ }^{236} \mathrm{Pu},{ }^{237} \mathrm{~Np},{ }^{234} \mathrm{U}\right.$, and $\left.{ }^{241} \mathrm{Am}\right)$, plutonium isotopic composition, and non-actinide cationic and anionic impurities analyses. The data obtained from these measurements provide baseline parameters for processing, waste disposal, and product certifications.

In preparation of pending heat source production for the future space missions (Mars Rover Twins, 2003; Europa Orbiter, 2004; Pluto-Kuiper Express, 2004; Solar Probe, 2007) [NASA, 2000], LANL ${ }^{238} \mathrm{Pu}$ group is implementing full-scale aqueous scrap recovery (ASR) operations. The ${ }^{238} \mathrm{Pu}$ analytical capabilities are being relocated to the Plutonium Facility due to the source term and material-at-risk issues at the aging CMR Facility (Chemistry Metallurgy Research building). In addition, several in-line processing monitoring capabilities are being installed in the full-scale ASR operations.

\section{CHEMICAL SPECIFICATIONS}

A general-purpose heat source (GPHS) or a lightweight radioisotope heater unit (LWRHU) is a ${ }^{238} \mathrm{PuO}_{2}$ fueled heat source designed to provide thermal power for space missions. Radioisotope thermoelectric generators (RTGs) which are powered by GPHS capsules and LWRHU heat sources provide electric power for spacecraft's science instruments and on-board computers. Between 1994 to 1997, LANL produced and delivered 235 GPHS capsules and 180 LWRHUs for the Cassini Mission. To ensure the quality of the fuel pellets for GPHSs or LWRHUs, ${ }^{238} \mathrm{PuO}_{2}$ feed materials and fuel powder must meet a set of chemical specifications. Table I. gives the chemical specifications of ${ }^{238} \mathrm{PuO}_{2}$ feed powders and ${ }^{238} \mathrm{PuO}_{2}$ fuel pellets [GPHS Specification, 1996].

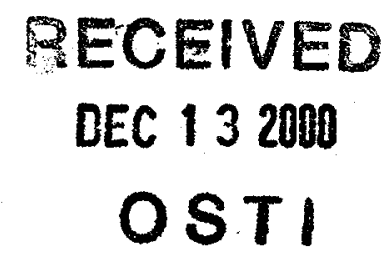


TABLE I. Chemical Specifications for the General Purpose Heat Source (GPHS, 1996)

\begin{tabular}{|c|c|}
\hline Requitement & Specification \\
\hline${ }^{238} \mathrm{Pu}$ Content & $\begin{array}{l}\geq 82 \% \text { of the total plutonium isotopes, } \\
\text { as of the date of precipitation }\end{array}$ \\
\hline${ }^{236} \mathrm{Pu}$ Content & $\begin{array}{c}<2 \mu \mathrm{g} / \mathrm{g} \text { of the total plutonium content, } \\
\text { as of the date of precipitation }\end{array}$ \\
\hline \multicolumn{2}{|c|}{ Actinide Impurities } \\
\hline Total (U, Th, Am, and Np) & $\leq 1 \%$ \\
\hline Individual actinide & $\leq 0.5 \%$ \\
\hline \multicolumn{2}{|c|}{ Nonactinide Impurities } \\
\hline$P$ & $\leq 25 \mu \mathrm{g} / \mathrm{g}$ \\
\hline 14onactinide Cation Impurities & $\begin{array}{l}\text { Maximum Allowable Concentrafion, } \\
\text { ug/g fuel powder. }\end{array}$ \\
\hline Total (all cation impurities) & $\leq 2550$ \\
\hline Total ( $\mathrm{Si}, \mathrm{Mg}, \mathrm{Ca}$, and $\mathrm{Al}$ ) & $\leq 1500$ \\
\hline $\mathrm{Al}$ & 500 \\
\hline $\mathrm{B}$ & 5 \\
\hline $\mathrm{Be}$ & 5 \\
\hline $\mathrm{Ca}$ & 300 \\
\hline $\mathrm{Cd}$ & 50 \\
\hline $\mathrm{Cr}$ & 500 \\
\hline $\mathrm{Cu}$ & 200 \\
\hline $\mathrm{Fe}$ & 800 \\
\hline $\mathrm{Mg}$ & 100 \\
\hline $\mathrm{Mn}$ & 50 \\
\hline Mo & 250 \\
\hline $\mathrm{Na}$ & 250 \\
\hline $\mathrm{Ni}$ & 500 \\
\hline $\mathrm{Pb}$ & 100 \\
\hline $\mathrm{Si}$ & 750 \\
\hline $\mathrm{Sn}$ & 50 \\
\hline $\mathrm{Zn}$ & 50 \\
\hline
\end{tabular}

\section{CHEMICAL ANALYSIS CAPABILITES}

LANL Analytical Chemistry Group at the CMR Facility has supported the chemical analyses of ${ }^{238} \mathrm{Pu}$ fuel powder. The analytical chemistry laboratories are located in the CMR building, which was constructed in 1952. Though once considered a state-of-the art facility, CMR is now nearing the end of its original design lifetime. A major effort is taking place to consolidate all the ${ }^{238} \mathrm{Pu}$ activities, including analytical chemistry, at the Plutonium Facility for reducing the material-at-risk limit elsewhere at LANL.

In the summer of 1999, NMT-9 Group has begun to establish the analytical capabilities for product certification and process monitoring at the TA-55 Plutonium Facility ${ }^{238} \mathrm{Pu}$ Fuel Processing Area. Several phases of this project will be implemented over the next several years. Three major capabilities include Pu assay, radiochemical analyses, and trace element analyses. Phase I involves retrofitting existing gloveboxes for plutonium assay and radiochemical sample preparation. Phase II involves installing UV-visible spectrometer, integrated gamma-ray analysis system, alpha spectrometer, and gas proportional counter in the existing ${ }^{238} \mathrm{Pu}$ laboratory rooms. Direct-current arc spectrometer and its glovebox system will be set up during Phase III. In addition, an in-line Plutonium Process Monitoring (PPM) system will be used to support the full-scale ASR ion-exchange operation to minimize plutonium loss and maximize americium and uranium removal. A solution in-line alpha counter (SILAC) will be installed in the ASR hydroxide filtrate and ultrafiltration glovebox for in-line monitoring of alpha activity. This instrument will enable us to perform semi-quantitative determination of total alpha activity in the solution. By knowing the approximate alpha concentration, we can adjust the operating parameters for ultra-filtration process accordingly. Brief descriptions of the major chemical analysis capabilities are given in the next sections. 


\section{Plutonium Assay}

${ }^{238} \mathrm{PuO}_{2}$ is dissolved in concentrated $\mathrm{HCl}, \mathrm{HNO}_{3}$, and few drops of $\mathrm{HF}$ in a sealed-reflux tube. The dissolved solution is then quantitatively transferred and aliquoted for $\mathrm{Pu}$ assay by $\mathrm{UV}$-visible spectrometer, actinide impurities by radiochemical methods, phosphorus and thorium analysis by ICP-MS, and isotopic analysis by thermal ionization mass spectrometry. The purity of plutonium-238 materials is determined by the $\mathrm{Pu}$ (III) chloride spectrophotometric method. It requires an UV-visible spectrometer to determine the concentration of plutonium in the samples. Because the analysis is performed inside of contaminated gloveboxes, a fiber-optic interface option is used. The spectrophotometer is calibrated using a series of matrices matching ${ }^{239} \mathrm{Pu}$ solution standards.

\section{Actinide Impurities Analyses}

The actinide impurities $\left({ }^{241} \mathrm{Am},{ }^{237} \mathrm{~Np},{ }^{234} \mathrm{U}\right.$, and $\left.{ }^{236} \mathrm{Pu}\right)$ in ${ }^{238} \mathrm{Pu}$ oxides are determined by radiochemical methods. Samples are pretreated and prepared in the gloveboxes and open-front hoods. The samples are then counted using various nuclear instrumentation systems. These counting methods utilize high-resolution germanium detectors to identify specific radionuclides present in the samples and use a sodium iodide detector to obtain the extraction yield of the tracer $\left({ }^{239} \mathrm{~Np}\right)$. A gas proportional counter and an alpha spectrometer are used to determine total alpha concentration and specific alpha radionuclides.

The current radiochemical analysis dissolve $\sim 30 \mathrm{mg}$ of ${ }^{238} \mathrm{Pu}$ oxide in solution. A sample pretreatment is required using concentrated $\mathrm{HBr}$ and $\mathrm{Br}_{2}$. Then $\mathrm{Am}, \mathrm{Np}$, and $\mathrm{U}$ are separated through an anion exchange process [Bubernak, 1969]. Then these $\mathrm{Np}$ and $\mathrm{U}$ aliquots ( $>99.5 \%$ of Pu removed) are transferred to the open-front box for further sample preparation. ${ }^{241} \mathrm{Am}$ is analyzed by taking a direct aliquot of ${ }^{238} \mathrm{Pu}$ solution and counted on a gamma-ray counting system. The overall process is time consuming (5 days or longer), and hydrobromic acid and bromine are extremely corrosive. An alternative method [Maxwell, 1998] based on TEVA ${ }^{8}$ Resin (Eichrom Industries, Inc.) is currently under development specifically for ${ }^{238} \mathrm{Pu}$ analysis.

\section{Trace Elements Analysis}

Currently two techniques are used to determine non-actinide cationic and anionic impurities. One is direct-current $\operatorname{arc}$ (DC Arc) spectrophotometry, and another one is inductively coupled plasma mass spectrometry (ICP-MS) for phosphorus and thorium analysis. DC Arc, a direct-solid analysis technique, was developed more than 50 years ago. The current DC Arc instrument at CMR utilizes photographic plates for recording sputtering signals from the samples. It requires a dark room for developing the photographic plates. Operations of DC Arc instrument are simple and reliable. However, the analysis results are not precise (20 to $50 \%)$, and require matrix-matching calibration.

Recently, a new DC Arc instrument was acquired. Instead of using the photographic plates, this system utilizes a charge injection device (CID) as the detector with digital recording. The preliminary design of the DC Arc interface glovebox system has been completed for the CMR facility. Because of the aging CMR facility issue, in FY00, the DC Arc equipment was relocated to the TA-55 cold-process laboratory for development and testing before being permanently installed in the Plutonium Facility. Improvements in data quality (precision and accuracy) and in analysis capabilities (background subtraction and digital spectral deconvolution) are expected using the new DC Arc instrument. This will greatly enhance our abilities to deliver on future space missions.

The second phase of the ${ }^{238} \mathrm{Pu}$ trace element analysis is to install a second capability (e.g., an ICP-MS, glowdischarge mass spectrometer, etc.) when lab space and funding become available.

\section{Plutonium Isotopic Analysis}

Plutonium isotopic compositions provide information about the enrichment of actinide materials for process certification of feed materials and products. The current analytical method for determining the isotopic composition of plutonium in a sample requires chemical separations followed by thermal ionization mass spectrometry (TIMS) analysis. This technique provides the most precise and accurate results (e.g., ${ }^{239} \mathrm{Pu}$ at $\pm 0.01 \%$ and ${ }^{240} \mathrm{Pu}$ at $\pm 0.1 \%$ ), 
however, it is a time-consuming and expensive process requiring highly skilled personnel to operate and maintain. The current plan for the Analytical Capabilities Project is to not relocate mass spectrometry, but to send dissolved ${ }^{238} \mathrm{PuO}_{2}$ to the Analytical Chemistry group for isotopic analysis. Because the isotopic information of ${ }^{238} \mathrm{Pu}$ materials is used to determine the weight percent of ${ }^{238} \mathrm{Pu}$ and is used for material control and accountability purpose, the precision and accuracy requirements for isotopic analysis may be more easily met by using alternative analysis method.

Nondestructive analysis (NDA) techniques based on gamma-ray spectroscopy have been developed for material control and accountability and special nuclear material safeguard applications. These techniques are specifically developed to measure large quantities (tens of grams to kilograms) of plutonium or uranium in either solid or liquid form and have the ability to incorporate shielding parameters in the calculation. The typical accuracy and precision are 1-20\% depending upon the matrix homogeneity and knowledge of process. However, this methodology has not been tested and applied to analytical applications where the sample size is in the milligram to nanogram range.

By applying the NDA techniques to analytical analysis, one can obtain rapid (a few hours or less), precise, and accurate analytical isotopic composition data for plutonium oxides. It has been demonstrated that one can achieve $1 \%$ or better precision and accuracy for analyzing ${ }^{239} \mathrm{Pu}$ materials. However, the current NDA analysis routines (MGA, Multi-Group Analysis, developed by Livermore; and PC/FRAM, fixed energy response function analysis with multiple efficiencies, developed by Los Alamos) [Abousahl,, 1995; Sampson, 1998], do not have the ability accurately predicting ${ }^{240} \mathrm{Pu}$ isotope data in ${ }^{238} \mathrm{Pu}$ materials due to the low ${ }^{240} \mathrm{Pu}$ enrichment. It will require modeling the isotopic data for determining the correction parameters of ${ }^{240} \mathrm{Pu}$ in ${ }^{238} \mathrm{Pu}$ materials. A project has been proposed by the LANL NMT-9 group and the University of Missouri-Rolla in the collaboration with LANL NIS-5 Safeguard Group. The proposed project will also require studying the effects of sample size, geometry, and matrix, as well as developing measurement protocols for a system that will maximize versatility, accuracy, and precision of NDA detection. Upon successful development of this method, we can utilize the integrated gamma-ray measurement system to provide on-site analytical isotopic analysis for ${ }^{238} \mathrm{Pu}$ materials.

\section{Plutonium Process Monitoring System}

The Plutonium Process Monitoring system utilizes the latest digital electronics and gamma-ray detector to monitor characteristic gamma rays from $\mathrm{Am}, \mathrm{U}$, and $\mathrm{Pu}$ [Wong, 2000]. The integrated data acquisition software enables us to obtain real-time trend plot and anion-exchange profiles (loading, washing and elution steps) within a few seconds. The PPM system will be installed in the full-scale ASR ion-exchange glovebox line to support minimization of solution and waste generation. Figure I. shows a simulated trend plot for anion-exchange operation.

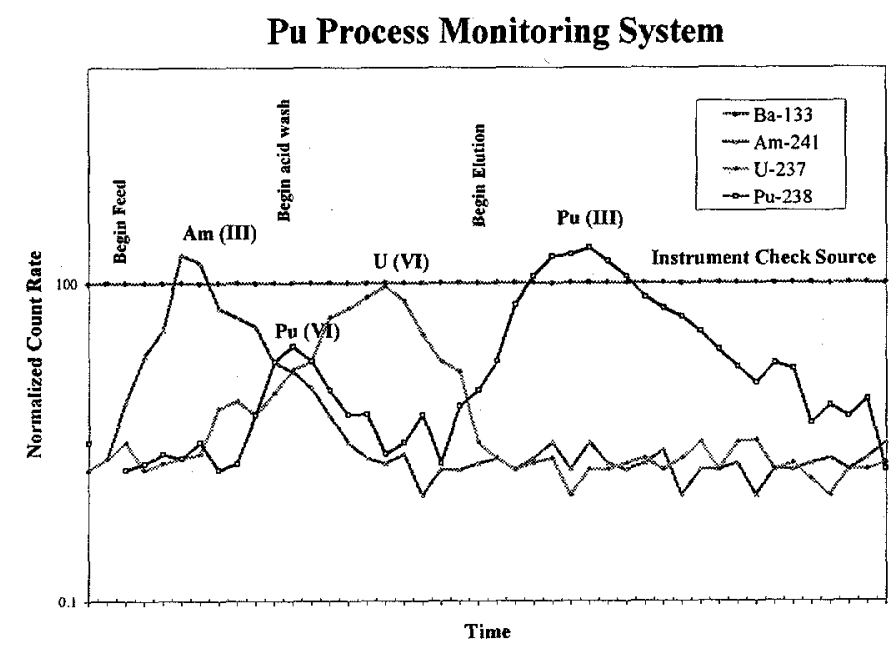

Figure 1. Simulated Trend Plot Data 


\section{CONCLUSIONS}

Significant progress has been made toward establishing analytical capabilities at the Plutonium Facility over the past year. Analytical and nuclear instrumentation systems were procured and received and are currently being tested in the NMT-9 cold-process laboratories. The analytical chemistry operations are in the process of being formally reviewed for work authorization, and the glovebox design and retrofit has been initiated. Phases I and II of Analytical Capabilities (Pu Assay and Radiochemical Analysis) are anticipated to be in place by the end of 2001; and Phase III (DC Arc trace element capabilities) in late 2001.

\section{ACKNOWLEDGMENTS}

We thank Liz Foltyn, Tim George, Gary Rinehart, and Kevin Ramsey for leading the efforts of the ${ }^{238}$ Pu programs at Los Alamos. We would like to acknowledge the continued support of the U. S. Department of Energy, Office of Nuclear Energy, Science, and Technology.

\section{REFERENCES}

Abousahl, S. Michiels, A., Bickel, M., Gunnink, R., and Verplancke, J., "The MGA Code for the Determination of the Isotopic Composition of Plutonium and MOX by Gamma Spectrometry - A Performance Study," Nucl. Inst. \& Methods, A, 368 449-456, (1996).

Bubernak, J, Lew, M. S. and Matlack, G. M. "Ion Exchange, Extraction, Separation and Radiochemical Determination of Neptunium-237 in Plutonium-238," Analytica Chimica Acta, 48, 233-241(1969).

GPHS 238-Plutonium Dioxide Specifications, Los Alamos National Laboratory Memo: NMT-9/ADM:96-053 (Drawing Number: 26Y-318180, Rev. A; Drawing Number 26Y-318181, Rev. C), 1996.

Maxwell, S. L., "Rapid Actinide-Separation Methods," Radioactivity \& Radiochemistry, 8, 36-44 (1998).

NASA/JPL Space Science Homepage, (http://www.jpl.nasa.gov), August 2000.

Sampson, T. E., "Gamma-Ray Isotopic Analysis Development At Los Alamos," Los Alamos National Laboratory, LA-UR-98-4206, 1998.

Wong, A. S., Ricketts, T. E., Pansoy-Hjelvik, M. E., Ramsey, K. B., Hansel, K. M., and Romero, M. K., "Plutonium Process Monitoring System," AIP Conference Proceeding, 532, 329-330 (2000). 